\title{
Association of Overweight, Obesity and Abdominal Obesity with Socioeconomic Status and Educational Level in Colombia
}

This article was published in the following Dove Press journal: Diabetes, Metabolic Syndrome and Obesity: Targets and Therapy

\author{
Mario A Jimenez-Mora' \\ Luz D Nieves-Barreto' \\ Angélica Montaño- \\ Rodríguez' \\ Eddy C Betancourt- \\ Villamizar ${ }^{2}$ \\ Carlos O Mendivil (1) ${ }^{1,3}$ \\ 'Universidad de los Andes, School of \\ Medicine, Bogotá, Colombia; ${ }^{2}$ Team \\ Foods, Bogotá, Colombia; ${ }^{3}$ Fundación \\ Santa Fe De Bogotá, Section of \\ Endocrinology, Bogotá, Colombia
}

\begin{abstract}
Objective: Latin American countries are experiencing a nutritional and demographic transition that predisposes to the spread of the obesity epidemic, especially among the socially and economically disadvantaged. We aimed to describe the prevalence of obesity, overweight and abdominal obesity and their association with household socioeconomic status (SES) and personal educational level in the five major cities of Colombia (Bogotá, Medellín, Cali, Barranquilla and Bucaramanga).
\end{abstract}

Materials and Methods: We collected demographic and anthropometric measurements from a population-based, stratified, multi-stage probability sample of individuals aged 2-75 years. Study surveys and anthropometric measurements were administered by highly trained staff. All reported prevalences are expanded to the target population, taking into account the sampling design.

Results: The study sample included 1922 participants. In children and adolescents, the prevalence of overweight and obesity were respectively $23 \%$ and $8.8 \%$. Overweight was most prevalent in the $2-4(30.9 \%)$, followed by the 5-11 $(23.8 \%)$ and the $12-17$ age group (17.8\%). The combined prevalence of childhood overweight and obesity increased with SES ( $16.8 \%$ in the lowest vs $42.8 \%$ in the highest stratum). In adults (18-75 years), the prevalence of excess body weight was $57.5 \%$ (36.2\% overweight, $21.3 \%$ obesity), the prevalence of abdominal obesity was $34.4 \%$, all prevalences increased with age. Obesity was far more prevalent among adult women $(29.4 \%)$ than men $(12.6 \%)(p<0.001)$. Adult obesity and abdominal obesity decreased significantly and monotonically with SES and were most prevalent in individuals with the lowest educational level (35.3\% and 50.7\%, respectively). Almost $40 \%$ of overweight adults had abdominal obesity.

Conclusion: Obesity and abdominal obesity are highly prevalent in the urban population of Colombia, and much more frequent among adults of lower SES and educational level. Excess body weight affected more often children of higher SES. Public health measures are urgently needed to tackle the spread of the obesity epidemic in Colombia and other Latin American countries, with a focus on low-income and low-educational level segments of society.

Keywords: obesity, overweight, abdominal obesity, socioeconomic status, inequality, Latin America, epidemiology

\section{Introduction}

Excess body weight has been consistently associated with increased risk of allcause mortality and adverse health outcomes including cardiovascular disease, diabetes, chronic kidney disease, osteoarthritis, more than 10 types of cancer and impaired psychosocial function. ${ }^{1-3}$ The accumulation of central fat, through visceral
Correspondence: Carlos O Mendivil Email cmendivi@uniandes.edu.co 
adiposity and metabolic dysregulation, also imparts an independent and strong detrimental effect on morbidity and mortality. ${ }^{4,5}$ Even within the normal BMI range, having abdominal obesity almost doubles the risk of all-cause mortality. ${ }^{6}$ Obesity in childhood often coexists with micronutrient deficiencies and increases the chances of remaining overweight or obese through adulthood. ${ }^{7}$

The prevalence of underweight has decreased worldwide since 1980, whereas overweight and obesity have simultaneously increased. ${ }^{8,9}$ In 2015, it was estimated that excess body weight accounted for 4 million deaths and 120 million disability-adjusted life-years worldwide. ${ }^{1}$ Historically, the prevalence of excess body weight had been higher in economically developed compared to developing countries, ${ }^{10}$ but the rate of increase has started to level off in developed countries during the past decade. Meanwhile, developing countries have witnessed a steady increase in obesity rates, ${ }^{8}$ associated with a demographic and nutritional transition. ${ }^{11,12}$

The distribution of overweight and obesity varies widely according to age group, region, race, urbanization and socioeconomic status (SES). ${ }^{8,12,13}$ Nonetheless, most of the studies exploring these associations come from high-income countries, and the demographics of obesity in such context cannot be extrapolated to low- and medium-income countries. Thus, regional and country-specific data are much needed. As an example, obesity has been found to be inversely associated with urbanization in developed countries, while in developing countries the opposite seems to happen. ${ }^{14}$ Few studies have evaluated the sociodemographic correlates of obesity in Latin America. ${ }^{15}$ In these analyses, a lower SES was associated with a higher proportion of obesity among children and adults. ${ }^{15,16}$ It has also been postulated that the effect of a lower SES status on obesity risk is more pronounced in women. ${ }^{16}$ Data from the US National Health and Nutrition Survey collected between 2011 and 2014 showed a remarkable negative correlation between household income and childhood obesity. The relationship was even stronger when the educational level of the head of household was used as indicator of socioeconomic status. ${ }^{17}$ Similarly, data from the ISCOLE (International Study of Childhood Obesity, Lifestyle and the Environment) study, showed that the association between household income and childhood obesity is dependent on the social context. For countries with a low- or middle-human development index (HDI), greater household income was positively associated with risk, while for high HDI countries the opposite occurred. ${ }^{18}$ Further, in multiethnic societies, much of the increased risk for obesity attributed to race or ethnicity disappears after adjustment for household/district income. ${ }^{19}$

In Colombia, national examination surveys carried out in 2005, 2010 and 2015 have provided limited information on the distribution of obesity-related risk factors, and no data on the prevalence of central obesity. The rates of adult excess weight (overweight + obesity) in these surveys were: $46.0 \%(39.9 \%$ for men, 49.6\% for women) in ENSIN 2005, ${ }^{20} 51.1 \%$ (45.6\% for men, $55.1 \%$ for women) in ENSIN $2010^{21}$ and $56.5 \%$ (52.8\% for men, $59.6 \%$ for women) in ENSIN $2015 .{ }^{22}$ The national survey have also demonstrated an enormous increase of about $1 \%$ per year in the prevalence of childhood excess weight between 2010 and 2015 (from 18.8 to $24.4 \%$ ). ${ }^{22}$ Such steep increase parallels the trends observed in Mexico about a decade earlier, which suggests that Colombia is currently experiencing the middle phase of a demographic and nutrition transition. ${ }^{23}$ As the rapidly changing epidemiology of obesity and its distribution are largely unexplored in Colombia, there is an impending need for studies addressing this issue in our population. Colombia is a geographically, racially and culturally diverse country with marked differences among regions. The five most populated regions of the country are: i. The central plateau (administrative and economic center of the country), ii. The northern Caribbean region, with culture and costumes similar to those of Caribbean nations, iii. The Pacific coast, a very industrialized region but also with high indexes of poverty and where most of the Afro-Colombian population resides, iv. The northwestern or "paisa" region, where there are many local traditions and there is a larger degree of European and Jewish ancestry and v. The northeastern/Andean region, mostly cold, very mountainous and with a larger degree of indigenous ancestry. Given that the current demographics of Colombia reveal a mostly urban country $(81 \%$ of the total population), we aimed to describe the prevalence of obesity, overweight and abdominal obesity and their associated factors in a probabilistic sample of individuals from the main urban center in each of the five regions described above: Bogotá (Central plateau), Barranquilla (Caribbean region), Cali (Pacific region), Medellín (Northwest or "paisa" region) and Bucaramanga (Northeast/Andean region), in the framework of the Colombian Study of Nutritional Profiles (Estudio Colombiano de Perfiles Nutricionales - COPEN).

\section{Materials and Methods}

COPEN was a population-based, cross-sectional, multi-stage sampling survey designed to represent 5 cities, one from each of Colombia's major regions. The sampling frame was obtained from the last census of the Colombian population, 
cartography was obtained from the national geostatistical frame developed by the Colombian National Department of Statistics (Departamento Administrativo Nacional de Estadística - DANE) and data on socioeconomic level came from the National Superintendence of Public Services. In the first stage of sampling we selected cartographic sectors, within sectors we selected blocks (on average 8 per cartographic sector), within blocks we selected households, and within households we selected individual participants. In order to balance the sample by sex, in the evenly numbered side of each street we selected men from each selected household, while in the oddly numbered side of each street we selected women. Within each household, individuals were randomly selected employing a Kish grid, listing in each home males or females according to the household location. All individuals over the age of 2 were listed and a person was randomly selected. In the case of participants under the age of 13 , information was provided by the adult responsible for the participant. The sample was stratified by city, sex, age group and socioeconomic level of the household.

All data were collected between June and November, 2018. Information was captured using a tablet device containing digital forms with proper validation rules, developed for the study. All staff in charge of data collection was extensively trained by the study Principal Investigator. A random $10 \%$ of participants were re-contacted by phone in order to double-check the accuracy of the information provided on date of birth, sex, city of residence, marital status, job status, educational level and date of initial contact. With this design and including the design effect, the study sample yielded an overall sampling error of $2.2 \%$. The sampling errors for each city were respectively: Bogotá 4.0\%, Medellín 5.0\%, Cali 5.0\%, Barranquilla $5.6 \%$ and Bucaramanga $6.8 \%$.

\section{Participants}

Participants were individuals between the ages of 2 and 75 , residing in one of the five cities mentioned above. We excluded foreigners living in Colombia, individuals in hemodialysis or peritoneal dialysis therapy and persons with disabilities that precluded a reliable fulfillment of the study questionnaire. Sampling for the general COPEN study did not exclude pregnant or lactating women, but these individuals were excluded from analyses presented in this article.

\section{Measurements}

We collected information on sex, date of birth, household socioeconomic status, marital status, individual educational level and employment status using a standardized questionnaire. The socioeconomic level that we employed for analyses was the one registered in DANE for that particular block. After a brief introduction about the importance of the accuracy of the measurements to be performed, we measured height and weight in all participants, and waist circumference in patients aged 18 and older. Height was measured using a portable stadiometer supported on a firm surface, taking care that the patient was barefoot, standing right and with heels and calves touching the stadiometer. Weight was measured in a solar digital scale with $100 \mathrm{~g}$ sensitivity and $200 \mathrm{Kg}$ capacity, all study scales were calibrated simultaneously the day before the study start, and every week afterwards. Waist circumference was measured by a sitting observer, directly over the participant's skin, at the midpoint between the last rib and the anterosuperior iliac crest, using a flexible metallic measuring tape. All measurements were performed in duplicate, and if there was a between-measures discrepancy greater than $1 \mathrm{~cm}$ for height, $100 \mathrm{~g}$ for weight or $1 \mathrm{~cm}$ for waist circumference, a third measurement was collected. For analyses we used the average of each anthropometric measure.

In Colombia, socioeconomic level is classified by the Statistics Department DANE in 6 strata (with stratum 1 being the lowest and stratum 6 being the highest). Residential dwellings are classified according to their physical characteristics and environment. The methodology for this classification creates homogeneous strata taking as input information about land use, public utilities, access routes, topography, land valuation and property characteristics. The stratification unit is the sub-zone, corresponding generally to a block. Residential dwellings are classified in the predominant stratum of the sub-zone, as long as their characteristics do not differ ostensibly from the predominant conditions in the group. Otherwise, they are considered outliers and their stratum is assessed based on their particular characteristics. This information is very well established, updated and freely accessible for all the country. It also has a significant correlation with household income. $^{24}$ Given that sociodemographic, income and human development indicators are more similar for individuals living in strata 4 to 6 than among the other strata, ${ }^{25}$ we analyzed SES in four groups, corresponding to strata 1 , 
2, 3 and 4-6. For participants aged 18 and older, we interpreted BMI according to the cut points proposed by the World Health Organization (WHO): Underweight $(\mathrm{BMI}<18.5 \mathrm{Kg} / \mathrm{m} 2)$, normal weight $(\mathrm{BMI} \geq 18.5$ and $<25$ $\mathrm{Kg} / \mathrm{m} 2$ ), overweight (BMI $\geq 25$ and $<30 \mathrm{Kg} / \mathrm{m} 2$ ) and obesity $(\mathrm{BMI} \geq 30 \mathrm{Kg} / \mathrm{m} 2)$. For participants aged 24 to 59 months, we interpreted BMI according to the BMI-forage tables proposed by the $\mathrm{WHO}^{26}$ as follows: Overweight or at risk of overweight (Z-score $>1$ and $\leq 3$ ) and Obesity (Z-score $>3$ ). For participants 5 to 17 years old, we interpreted BMI according to the BMI-for-age tables proposed by the $\mathrm{WHO}^{26}$ as follows: Overweight (Z-score $>1$ and $\leq 2$ ) and obesity (Z-score $>2$ ). We analyzed BMI-for age data in underage participants using Anthro 3.22 for Stata 13 (College Station, TX). We defined abdominal obesity as a waist circumference $\geq 90 \mathrm{~cm}$ for women, and $\geq 94 \mathrm{~cm}$ for men, according to the proposed cutoffs for Latin American adults. ${ }^{27}$ Analyses involving educational level included only participants aged 18 or older.

\section{Data Analysis}

All prevalence estimations were projected to the target study population using city, sex, age group and SESspecific expansion factors according to the study multistage sampling design. The associations between nominal predictors and overweight, obesity and abdominal obesity were examined using chi-square independence tests. To test for a linear trend in the association between ordinal predictors and overweight, obesity and abdominal obesity, we report the p-value associated with a rank-correlation (Spearman) test between predictor and outcome. We also ran multivariable logistical models in which sociodemographic variables were the independent variables and overweight/obesity or abdominal obesity were the outcomes, separately for children and adults. All analyses were performed in SPSS for Windows, v.21 (Cary, NC, USA).

\section{Ethical Aspects}

Participants aged 14-75 provided written informed consent, and a parent or legal guardian provided written informed consent for all participants under the age of 14 years. In addition participants aged 7-13 provided written assent, while in the case of participants aged 2-6, informed consent was provided by the adult responsible for the child. All study procedures were performed according to the principles of the Helsinki Declaration, and to local rules and regulations as provided by Resolution 8430 of 1993 of the Colombian Ministry of Health. The study was approved by the IRB of Universidad de los Andes (Comité de Ética de la Vicerrectoría de Investigaciones), according to minute 1016 of April 27, 2018.

\section{Results}

\section{Characteristics of the Study Sample}

The study sample included 1922 participants (1537 adults and 385 children), with equal representation from both sexes (Table 1). Most participants were residents of Bogotá, followed in order by Medellín, Cali, Barranquilla and Bucaramanga. According to Colombia being a low-middle income country, most participants belonged to households in SES strata 2 or 3, while only a tenth of participants lived in SES strata 5 and 6. Approximately two thirds of study participants had a high school or lower educational level, and only a minority had attained college or higher degrees. Among adult participants, average body-mass index (BMI) was $27.1 \mathrm{~kg} / \mathrm{m} 2$, being higher in women $(28.2 \mathrm{~kg} / \mathrm{m} 2)$ than men $(25.9 \mathrm{~kg} / \mathrm{m} 2)$. Mean waist circumference, on the other hand, was higher in men $(90.2 \mathrm{~cm})$ than women $(87.8 \mathrm{~cm})$.

\section{Overweight and Obesity in Children and Adolescents}

The overall prevalence of overweight and obesity were $23.3 \%$ and $8.8 \%$, respectively, based on BMI-for-age standards (Table 2). Overweight rates decreased with age, while obesity prevalence was much higher in children aged 5-11 years compared to the rest of the age groups $(p<0.001)$. On average, boys tended to be more overweight and obese than girls. Overweight and obesity rates were lowest in Barranquilla, intermediate in Bucaramanga and Bogotá, and highest in Cali and Medellín (Figure 1A). The prevalence of excess body weight increased drastically with SES, more than doubling from stratum $1(16.7 \%)$ to strata 4-6 (42.8\%) (p-trend $<0.001$, Figure $2 A)$.

\section{Overweight and Obesity in Adults}

The prevalence of adult overweight $(25<\mathrm{BMI}<30)$ was $36.2 \%$ and the prevalence of adult obesity $(\mathrm{BMI} \geq 30)$ was $21.3 \%$ (Table 3 ). The prevalence of obesity among adult women was more than twice as high as in men $(\mathrm{p}<0.001)$. The combined prevalence of adult overweight and obesity increased monotonically across age groups, climbing to $72.2 \%$ in the $\geq 60$ age group (p-trend $<0.001$, Table 3 ), and was highest in Barranquilla, followed in order by Bucaramanga, Cali, Bogotá and Medellín (Figure 1B). 
Table I Demographic and Anthropometric Characteristics of the Study Participants

\begin{tabular}{|c|c|c|c|c|c|c|}
\hline & \multicolumn{3}{|c|}{ Adults (Age $>=\mid 8$ ) } & \multicolumn{3}{|c|}{ Children and Adolescents $($ Age $<18)$} \\
\hline & Male & Female & Total & Male & Female & Total \\
\hline$n$ & $723(47.0)$ & $814(53.0)$ & 1537 & $237(61.6)$ & $148(38.4)$ & 385 \\
\hline \multicolumn{7}{|l|}{ Age group, years } \\
\hline 2 to $<5$ & - & - & - & $47(19.8)$ & $40(27.0)$ & $87(22.6)$ \\
\hline 5 to 11 & - & - & - & $99(4 \mid .8)$ & $46(31.1)$ & $145(37.7)$ \\
\hline 12 to 17 & - & - & - & $91(38.4)$ & $62(41.9)$ & $153(39.7)$ \\
\hline 18 to 39 & $316(43.7)$ & $320(39.3)$ & $636(4 \mid .4)$ & - & - & - \\
\hline 40 to 59 & $212(29.3)$ & $269(33.0)$ & $48 I(3 I .3)$ & - & - & - \\
\hline 60 to 75 & $195(27.0)$ & $225(27.6)$ & $420(27.3)$ & - & - & - \\
\hline \multicolumn{7}{|l|}{ Socioeconomic stratum* } \\
\hline I & $91(12.6)$ & $116(14.3)$ & $207(13.5)$ & 61 (25.7) & $32(21.6)$ & $93(24.2)$ \\
\hline 2 & $198(27.4)$ & $225(27.6)$ & $423(27.5)$ & $80(33.8)$ & $50(33.8)$ & $130(33.8)$ \\
\hline 3 & $220(30.4)$ & $240(29.5)$ & $460(29.9)$ & $70(29.5)$ & $51(34.5)$ & $121(31.4)$ \\
\hline $4-6$ & $214(29.6)$ & $233(28.6)$ & $447(29.1)$ & $26(\mathrm{II})$ & $15(10.1)$ & $4 I(10.6)$ \\
\hline \multicolumn{7}{|l|}{ City } \\
\hline Barranquilla & $121(16.7)$ & $124(15.2)$ & $245(15.9)$ & $34(14.3)$ & $28(18.9)$ & $62(16.1)$ \\
\hline Bogotá & $226(3 \mid .3)$ & $262(32.2)$ & $488(31.8)$ & $77(32.5)$ & $47(31.8)$ & $124(32.2)$ \\
\hline Bucaramanga & $72(10)$ & $96(11.8)$ & $168(10.9)$ & $32(13.5)$ & $12(8.1)$ & $44(11.4)$ \\
\hline Cali & $145(20.1)$ & $167(20.5)$ & $312(20.3)$ & $60(25.3)$ & $34(23)$ & $94(24.4)$ \\
\hline Medellín & $159(22)$ & $165(20.3)$ & $324(21.1)$ & $34(14.3)$ & $27(18.2)$ & $61(15.8)$ \\
\hline \multicolumn{7}{|l|}{ Educational level** } \\
\hline Elementary school or less & $142(19.6)$ & $179(22.0)$ & $321(20.9)$ & & & \\
\hline High school & $30 I(4 I .6)$ & $324(39.8)$ & $625(40.7)$ & & & \\
\hline Technical or associate degree & $130(18.0)$ & $15 \mid(18.6)$ & $28 \mid(18.3)$ & & & \\
\hline College or higher & $150(16.1)$ & $160(19.7)$ & $310(20.2)$ & & & \\
\hline
\end{tabular}

Notes: Data are expressed as n (percentage). *SES According to Colombia's official Statistics Department-DANE, using criteria about land use, public utilities, access routes, topography, land valuation and property characteristics of the property inhabited by the household. SES I is lowest and SES 6 is highest. **Reported and analyzed only for participants aged 18 or older.

Conversely, both obesity ( $\mathrm{p}$-trend $=0.001$ ) and combined overweight/obesity ( $\mathrm{p}$-trend $=0.009$ ) decreased as SES increased (Figure 2B). A similar pattern was observed for educational level, as obesity prevalence in the lowest educational level doubled that of participants with college or higher education ( $\mathrm{p}$-trend $<0.001$, Table 3 ).

\section{Abdominal Obesity in Adults}

The total prevalence of abdominal obesity was $34.4 \%$, and also increased markedly and consistently with age, almost tripling between from the youngest to the oldest age group (Table 3, Figure 3B). Abdominal obesity displayed large differences by sex: For ages below 60 it was much more prevalent in women than men, but for ages 60 and older the opposite was true (Figure 3B). In contrast to overweight/ obesity, the trend across SES was not as pronounced as for age groups. However, abdominal obesity did show a strong association with education, being highest by a large margin in the lowest educational level (p-trend $<0.001$ ). We found the highest prevalence of abdominal obesity in Barranquilla, followed in order by Cali, Bucaramanga, Medellin and Bogotá (Table 3, Figure 3A). Since persons with overweight but increased abdominal fat may carry metabolic risks similar to persons with overt obesity, we analyzed the proportion of adults classified as overweight by their BMI who also presented abdominal obesity (Figure 4). This proportion was surprisingly large: $46 \%$ among men and $33 \%$ among women.

\section{Multivariable Models}

In a mutually adjusted logistical model among children and adolescents $(\operatorname{age}<18)$ that included sex, age, city of residence and SES as covariates, only SES was an independent predictor of excess weight (overweight or obesity) ( $p=0.006)$. Relative to SES 1 , the ORs for excess weight were 2.28 for SES 2 (95\% CI: 1.10-4.71), 2.76 for SES 3 (95\% CI: $1.34-5.68)$ and 4.56 for SES 4-6 
Table 2 Prevalence and Distribution of Overweight and Obesity in Colombian Urban Children

\begin{tabular}{|c|c|c|c|c|c|c|}
\hline & Overweight & p-value* & p-Trend** & Obesity & p-value* & p-Trend $* *$ \\
\hline Overall & 23.3 & - & - & 8.8 & - & - \\
\hline \multicolumn{7}{|l|}{ Sex } \\
\hline Boys & 25.4 & 0.53 & NA & 10.0 & 0.80 & NA \\
\hline Girls & 21.2 & & & 7.6 & & \\
\hline \multicolumn{7}{|c|}{ Age group, years } \\
\hline 2 to $<5$ & 30.9 & 0.09 & 0.031 & 1.0 & $<0.001$ & 0.84 \\
\hline 5 to 11 & 23.8 & & & 17.3 & & \\
\hline 12 to 17 & 17.8 & & & 5.3 & & \\
\hline \multicolumn{7}{|c|}{ Socioeconomic stratum $* * *$} \\
\hline I & 13.0 & 0.075 & 0.25 & 3.7 & 0.012 & $<0.001$ \\
\hline 2 & 25.7 & & & 4.8 & & \\
\hline 3 & 23.7 & & & 8.2 & & \\
\hline $4-6$ & 25.4 & & & 17.4 & & \\
\hline \multicolumn{7}{|l|}{ City } \\
\hline Barranquilla & 10.7 & 0.12 & NA & 12.5 & 0.30 & NA \\
\hline Bogotá & 23.9 & & & 5.5 & & \\
\hline Bucaramanga & 15.2 & & & 14.1 & & \\
\hline Cali & 28.2 & & & 8.5 & & \\
\hline Medellín & 24.4 & & & 18.9 & & \\
\hline
\end{tabular}

Notes: For participants aged 24 to 59 months, overweight was defined as a BMI-for-age Z-score $>$ I and $\leq 3$, and obesity as a Z-score $>3$. For participants aged 5 to I7 years, overweight was defined as a BMI-for-age Z-score $>I$ and $\leq 2$, and obesity as a Z-score $>2$. Data are expanded prevalence rates (\%). $* P$-value for the chi-square test, indicates whether at least one category is significantly different from the others. ${ }^{*}$ P-value for the ordinal correlation test, indicates whether there is a significant trend across categories. ***SES According to Colombia's official Statistics Department-DANE, using criteria about land use, public utilities, access routes, topography, land valuation and property characteristics of the property inhabited by the household. SES I is lowest and SES 6 is highest.

Abbreviation: NA, not applicable.

(95\% CI: 1.86-11.1). In a similar model for adults that additionally included educational level, SES was again an independent predictor of excess body weight $(\mathrm{p}<0.001)$. Relative to SES 1, being in SES 4-6 was associated with $40 \%$ lower odds of having excess body weight (OR 0.60, 95\% CI: 0.40-0.90). The ORs for SES 2 (1.20, 95\% CI: 0.83-1.75) and 3 (0.93, 95\% CI: $0.64-$ 1.36) were not statistically significant. Being a resident of Bogotá (OR 0.61, 95\% CI: 0.43-0.87) or Medellín (OR 0.49, 95\% CI: 0.33-0.71) was also associated with lower odds of excess body weight. On the other hand, being 60 or older was the strongest correlate of abdominal obesity (OR versus age 18-39: 5.71, 95\% CI: 4.22-7,72). Female sex was independently and positively associated with abdominal obesity (OR 1.26, 95\% CI 1.01-1.57), while living in Bogotá (OR 0.41, 95\% CI: 0.29-0.59) or Medellín (OR 0.51, 95\% CI: 0.35-0.75) were negatively associated with it.

\section{Discussion}

In this population-based, probabilistic study of children and adults from the 5 most important Colombian cities, we report an alarmingly high prevalence of overweight, obesity and abdominal obesity in both sexes. The city of residence (with its associated culture and gastronomy), age and socioeconomic stratum were also important correlates of adiposity measures. We followed a complex multi-stage sampling scheme, took all measurements at least in duplicate by highly trained staff, and employed high-quality, well calibrated equipment.

The most striking finding from this study was the impressively high prevalence of excess body weight among children and adolescents: one out of three children suffers from overweight or obesity. Such a high rate represents an increase compared to previously reported data from the 2015 national survey, ${ }^{22}$ in which excess body weight prevalence was $24.4 \%$ for the 5-12 age group and $17.9 \%$ for the $13-17$ age group. This difference can be explained, in part, by the inclusion of participants from both urban and rural areas in the national survey, in which the urban prevalence was $3-8 \%$ higher than its rural counterpart; a pattern that has been observed in several studies in low- and middle-income countries. ${ }^{28}$ Differences in methodology may have also played a role. Nevertheless, 


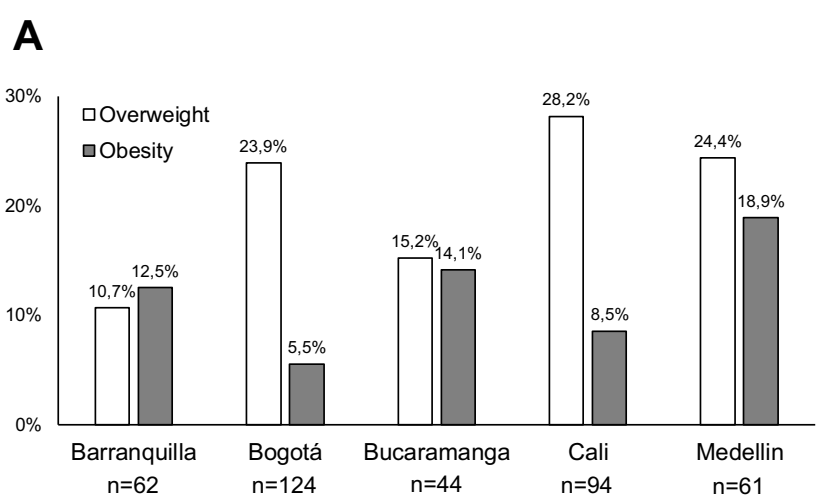

B

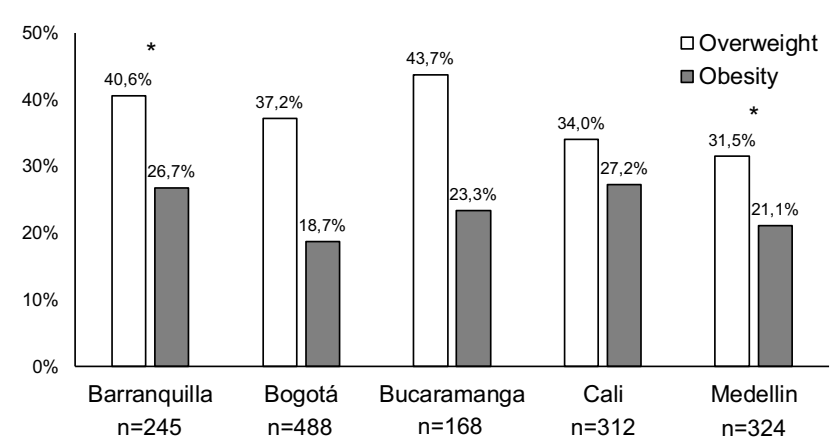

Figure I Prevalence of overweight and obesity in Colombian urban children and adolescents (ages 5 to 17, Panel (A)) and urban adults (ages I 8 to 75, Panel (B)), by city. Note: ${ }^{*} \mathrm{p}<0.05$ for the difference in prevalence versus the other cities.

having included only children from the urban setting cannot fully account for the magnitude of the difference between the two studies, which more likely reflects an increase in childhood obesity during the last 5 years. Interestingly, we observed among children and adolescents a higher prevalence of overweight in younger age groups (Table 1), a trend that, if continued with each new generation, will have a profound public health impact. When comparing the prevalence of overweight and obesity among countries from the Latin America region, there exists significant heterogeneity, reflecting different stages of the obesity epidemic, ${ }^{8,23,28}$ and of the socioeconomic and nutritional transition. For example, a population-based study in Peru revealed a much lower prevalence of excess body weight $(6.9 \%)$ in children under age 5 years, compared to our findings. ${ }^{29}$ Conversely, a cross-sectional study in Brazil $^{30}$ showed a $30.3 \%$ prevalence of excess body weight in adolescents, which is higher than the one we report for that age group. Compared to our study, the official national survey of Mexico ${ }^{31}$ revealed a lower prevalence of excess body weight among children aged 5-11 $(33.2 \%$ vs $41.1 \%)$, but a higher prevalence in children
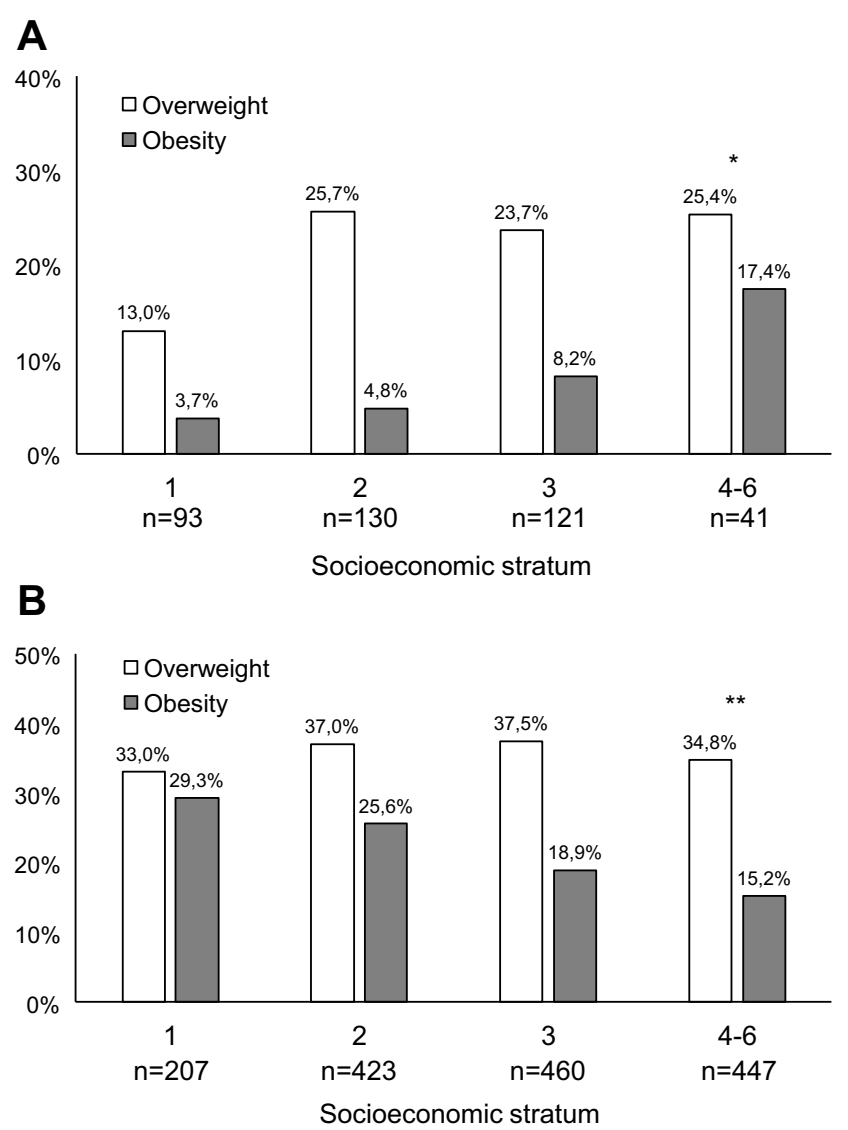

Figure 2 Prevalence of overweight and obesity in Colombian urban children and adolescents (ages 5 to 17, Panel (A)) and urban adults (ages 18 to 75, Panel (B)), by socioeconomic stratum.

Notes: *P-trend $<0.00 \mathrm{I}$ for the increase in the combined prevalence of overweight + obesity across socioeconomic strata for children and adolescents. $* * P$-trend $=0.009$ for the decrease in the combined prevalence of overweight + obesity across socioeconomic strata for adults.

aged $12-19$ (36.3\% vs $23.1 \%)$. The Mexican study did not find statistically significant changes between 2012 and 2016, which indicates that Mexico may be experiencing a later stage of the obesity epidemic. The rise in childhood obesity prevalence is not an isolated phenomenon of our country or region, it has also been observed in other lowand middle-income countries like South Africa. ${ }^{32}$

We found that an alarming proportion of our adult population - almost sixty percent - suffers from overweight or obesity. In the three prior versions of the Colombian National Survey, the combined prevalence of overweight and obesity increased steadily from $45.9 \%$ in 2005 to $51.2 \%$ in 2010 and $56.5 \%$ 1n $2015 .^{20-22}$ Our results show a smaller increment to $57.5 \%$, suggesting a deceleration of the obesity epidemic among adults in Colombia. However, our findings show that such deceleration is taking exclusively among men, as the prevalence of excess weight for adult women was $49.8 \%$ in $2005,55.2 \%$ in $2010,59.6 \%$ in 2015 and $65.4 \%$ in our study. Women have on 
Table 3 Prevalence and Distribution of Overweight, Obesity and Abdominal Obesity Among Colombian Urban Adults

\begin{tabular}{|c|c|c|c|c|c|c|c|c|c|}
\hline & Overweight & p-value* & p-Trend** & Obesity & p-value* & p-Trend** & $\begin{array}{l}\text { Abdominal } \\
\text { Obesity }\end{array}$ & p-value* & p-Trend** \\
\hline Overall & 36.2 & - & - & 21.3 & - & - & 34.4 & - & - \\
\hline \multicolumn{10}{|l|}{ Sex } \\
\hline Men & 36.4 & 0.15 & NA & 12.6 & $<0.001$ & NA & 29.5 & 0.019 & NA \\
\hline Women & 36.0 & & & 29.4 & & & 38.8 & & \\
\hline \multicolumn{10}{|l|}{ Age group } \\
\hline 18 to 39 & 28.9 & $<0.001$ & $<0.001$ & 14.7 & $<0.001$ & $<0.001$ & 19.2 & $<0.001$ & $<0.001$ \\
\hline 40 to 59 & 42.3 & & & 27.7 & & & 44.8 & & \\
\hline 60 to 75 & 44.9 & & & 27.3 & & & 58.1 & & \\
\hline \multicolumn{10}{|l|}{ Socioeconomic stratum $* * * *$} \\
\hline 1 & 33.0 & 0.12 & 0.80 & 29.3 & 0.004 & 0.001 & 38.6 & 0.47 & 0.16 \\
\hline 2 & 37.0 & & & 25.6 & & & 38.7 & & \\
\hline 3 & 37.5 & & & 18.9 & & & 31.0 & & \\
\hline $4-6$ & 34.8 & & & 15.2 & & & 31.3 & & \\
\hline \multicolumn{10}{|l|}{ City } \\
\hline Barranquilla & 40.6 & 0.39 & NA & 26.7 & 0.57 & NA & 47.1 & 0.13 & NA \\
\hline Bogotá & 37.2 & & & 18.7 & & & 29.4 & & \\
\hline Bucaramanga & 43.7 & & & 23.3 & & & 38.7 & & \\
\hline Cali & 34.0 & & & 27.2 & & & 40.6 & & \\
\hline Medellin & 31.5 & & & 21.1 & & & 36.5 & & \\
\hline \multicolumn{10}{|l|}{ Educational level } \\
\hline Elementary school or lower & 36.2 & 0.086 & 0.28 & 33.5 & 0.008 & $<0.001$ & 50.7 & 0.002 & $<0.001$ \\
\hline High school & 32.6 & & & 20.7 & & & 32.4 & & \\
\hline Technical or associate degree & 36.0 & & & 16.8 & & & 26.6 & & \\
\hline College or higher & 43.9 & & & 15.9 & & & 31.2 & & \\
\hline
\end{tabular}

Notes: Overweight was defined as a BMI $\geq 25.0$ and $<30 \mathrm{Kg} / \mathrm{m} 2$, and obesity as a BMI $\geq 30 \mathrm{Kg} / \mathrm{m} 2$. Abdominal obesity was defined as as a waist circumference $\geq 90 \mathrm{~cm}$ for women, and $\geq 94 \mathrm{~cm}$ for men. Data are expanded prevalence rates (\%). *P-value for the chi-square test, indicates whether at least one category is significantly different from the others. **P-value for the ordinal correlation test, indicates whether there is a significant trend across categories. ***SES According to Colombia's official Statistics Department-DANE, using criteria about land use, public utilities, access routes, topography, land valuation and property characteristics of the property inhabited by the household. SES I is lowest and SES 6 is highest.

Abbreviation: NA, not applicable.

average a lower basal energy expenditure than $\operatorname{men}^{33}$ and have an increased susceptibility to excess adiposity after the menopausal transition. ${ }^{34}$ Also, women from developing countries tend to have on average a lower educational level and lower income than men, ${ }^{35}$ both factors that were positively associated with excess BMI in our study. These results must constitute a call to urgent public health action strongly focused on urban adult women, if the long-term consequences of excess weight are to be averted in this population segment. In general, the stabilization of the rates of increase in adult obesity and overweight seems to be a ubiquitous phenomenon throughout Latin America. ${ }^{9}$ In Mexico, although the prevalence of excess body weight is much higher $(72.5 \%)$ than in Colombia, very little change was observed between the 2012 and 2016 national surveys. ${ }^{31}$ Our study also exposed the fact that adult women in low- and middle-income countries seem to be disproportionately affected by the burden of overweight and obesity. ${ }^{8,36}$
Very little is known about the prevalence and distribution of abdominal obesity in low- and middle-income countries. ${ }^{37}$ In Colombia, few studies had addressed this question, and mostly through non-probabilistic samples, ${ }^{38,39}$ with reported prevalences varying widely between $39.2 \%$ and $67.0 \%$, due to different methods and definitions of abdominal obesity. In this study, about one third of the adults in urban Colombia had abdominal obesity, with vast differences among geographical regions. Compared to other Latin American countries, we found a lower prevalence of abdominal obesity than Mexico $(76.6 \%),{ }^{31}$ and a prevalence similar to that in countries on the southern cone (Argentina, Chile, Uruguay). ${ }^{15}$ Waist circumference is increasing at each BMI level and at all ages in low- to medium- income countries. ${ }^{37}$ An independent association between abdominal obesity and adverse health effects may not be entirely established for some developing countries (especially for those in South Asia and South Africa), ${ }^{36}$ but 

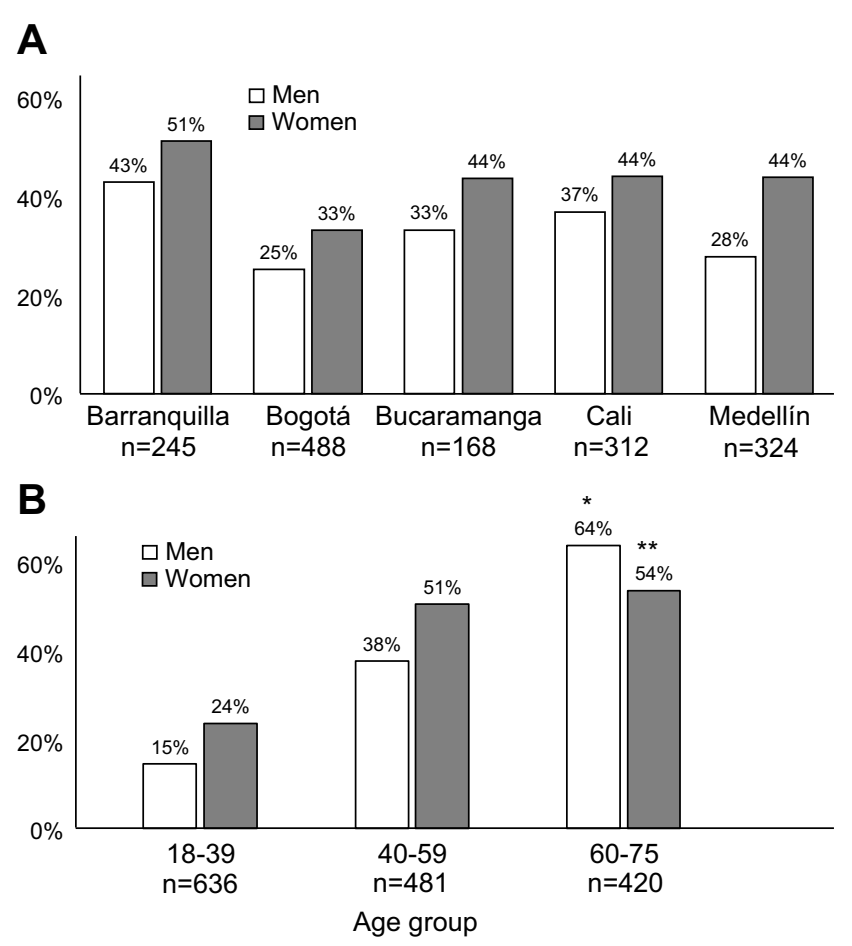

Figure 3 Prevalence of abdominal obesity in Colombian adults by city (panel (A)) and age (panel (B)).

Notes: *P-trend $<0.001$ for the increase in abdominal obesity across age-group categories in men. **P-trend $<0.001$ for the increase in abdominal obesity across age-group categories in women.

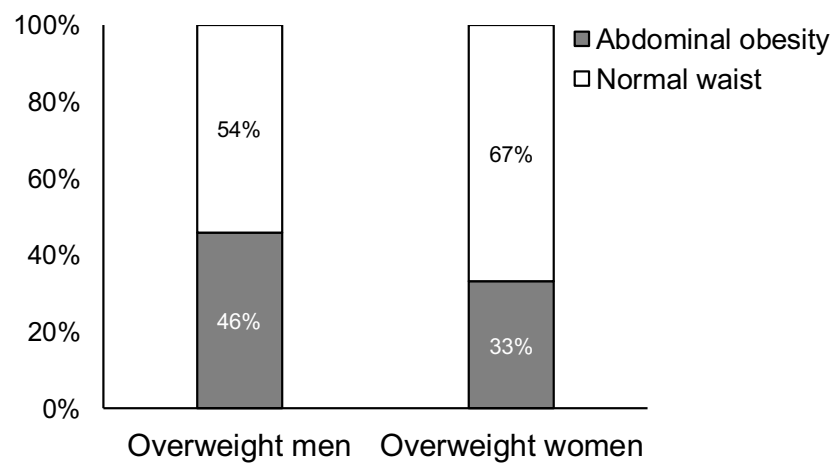

Figure 4 Waist circumference classification in Colombian overweight adults, by sex.

has already been proven for the Latin American population. ${ }^{40}$ Our study highlights the importance of assessing abdominal obesity in clinical practice and in public health, as we found a considerably high proportion of adults with abdominal obesity that would otherwise not be considered to suffer from obesity according to their BMI classification.

Colombia has experienced a rapid economic growth during the last two decades, as indicated by the increase in its gross national product (GNP) per capita, from U\$2340 in 2000 to U $\$ 6190$ in $2018 .^{41}$ Nonetheless, the country continues to exhibit one of the largest degrees of socioeconomic disparity in the region. ${ }^{42}$ Thus, we were particularly interested in understanding the impact of disparities on the prevalence of overweight and obesity. We had the unexpected finding that the association between SES and adiposity measures is markedly different for children and adults. Children from higher SES strata consistently showed increased rates of excess body weight, while among adults SES displayed a strong negative association with excess weight. As part of the so-called nutrition transition in emerging countries, it is frequent to observe a shift in the burden of obesity towards economically disadvantaged segments of society. ${ }^{14,43}$ With the progressive westernization of lifestyle and food habits that usually accompanies economic development, the cost of unhealthy, industrialized, caloriedense foods decreases, physical activity levels drop and chronic diseases become more prevalent among the poor. ${ }^{44}$ These factors may explain the inverse association we found between SES or educational level and obesity/abdominal obesity in adults. In children, we hypothesize that the nutrition transition has not yet taken place completely, ${ }^{28}$ perhaps due to cultural factors that limit the caloric intake of children in lower income families, but promote it in wealthier families (ie increased exposure to publicity for industrialized foods). Another possible explanation involves the increased caloric expenditure of economically disadvantaged children, coupled with the increased energy requirements necessary to sustain growth, ${ }^{45}$ in the context of relative food scarcity. Cultural beliefs about what a healthy child should look like may also play a role in the positive association between SES and childhood obesity.

All around the world, the prevalence of overweight and obesity rises with age, peaking around the sixth decade of life. ${ }^{8}$ Contributing factors include a lower metabolic rate associated with aging and changes in body composition such as a lower fat-free body mass and higher deposition of visceral fat. ${ }^{46}$ We were surprised, however, by the sharp changes observed after age 40, compared to the 18-39 age group: overweight increased by $50 \%$, obesity by $90 \%$, and abdominal obesity by $130 \%$ (Table 3, Figure 3B). This contrasts with findings from recent studies in both developing and developed countries. In Mexico, abdominal obesity prevalence was only $37 \%$ higher in the $40-49$, compared to the 20-29 age group. ${ }^{31}$ Similarly, in the southern cone of Latin America and in the United States, the prevalence of overweight, obesity and abdominal obesity does not show such marked differences across age groups. ${ }^{15,47}$ The public health implications of these data are especially concerning in Colombia, a country in which $37 \%$ of the population is 40 years or older; and should 
prompt efforts to prevent obesity in children and younger adults to reduce the burden of disease. An evidence-based strategy is aimed at increasing physical activity, which has demonstrated to lessen weight gain in young adults as they transition to middle age. ${ }^{48}$

The most important limitation of our study was the lack of information from Colombia's rural population. Even though Colombia is nowadays a mostly urban country, the disparity in chronic, non-communicable conditions between rural and urban populations can be quite substantial, especially in developing countries. ${ }^{49}$ Our study updates prior analyses that had shown no or very little association between SES or education in Colombia, particularly for women, and contribute to the overall picture of the obesity epidemic in Latin America. ${ }^{50}$ Future studies will need to be focused on rural populations from different geographical regions of the country, and on the sociodemographic correlates of adiposity in this context. Another relevant limitation is that we did not collect data on body composition, which can be a better estimator of energy metabolism disturbances, particularly among apparently normal-weight individuals. ${ }^{51}$ Further studies will need to explore these aspects.

\section{Conclusion}

Overweight, obesity and abdominal obesity are highly prevalent in the urban population of Colombia, and much more frequent among adults of lower socioeconomic levels. Public health measures are urgently needed in order to avert the obesity epidemic that has taken place in other countries of the region.

\section{Data Sharing Statement}

The datasets generated during and/or analyzed during the current study are available from the corresponding author on reasonable request.

\section{Acknowledgments}

We want to sincerely thank study participants for their invaluable collaboration. Even though this study was funded by Team Foods Colombia, it was executed independently by the study authors. The sponsoring company had no influence on data analysis, on the contents of the manuscript, or on the decision to publish.

\section{Author Contributions}

All authors made substantial contributions to conception and design, acquisition of data, or analysis and interpretation of data; took part in drafting the article or revising it critically for important intellectual content; gave final approval of the version to be published; and agree to be accountable for all aspects of the work.

\section{Funding}

This study was funded by Team Foods Colombia.

\section{Disclosure}

The authors report no conflicts of interest in this work.

\section{References}

1. Afshin A, Forouzanfar MH, Reitsma MB, et al. Health effects of overweight and obesity in 195 countries over 25 years. $N$ Engl J Med. 2017;377:13-27.

2. Aune D, Sen A, Prasad M, et al. BMI and all-cause mortality: systematic review and non-linear dose-response meta-analysis of 230 cohort studies with 3.74 million deaths among 30.3 million participants. $B M J$. 2016;353:i2156. doi:10.1136/bmj.i2156

3. Kyrgiou M, Kalliala I, Markozannes G, et al. Adiposity and cancer at major anatomical sites: umbrella review of the literature. $B M J$. 2017;356:j477. doi:10.1136/bmj.j477

4. Janssen I, Katzmarzyk PT, Ross R. Waist circumference and not body mass index explains obesity-related health risk. Am J Clin Nutr. 2004;79(3):379-384. doi:10.1093/ajen/79.3.379

5. Gnatiuc L, Alegre-Diaz J, Wade R, et al. General and abdominal adiposity and mortality in Mexico city: prospective study of 150000 adults. Ann Intern Med. 2019;171(6):397-405. doi:10.7326/M183502

6. Sahakyan KR, Somers VK, Rodriguez-Escudero JP, et al. Normalweight central obesity: implications for total and cardiovascular mortality. Ann Intern Med. 2015;163(11):827-835. doi:10.7326/ M14-2525

7. Whitaker RC, Wright JA, Pepe MS, Seidel KD, Dietz WH. Predicting obesity in young adulthood from childhood and parental obesity. $N \quad$ Engl $J \quad$ Med. 1997;337(13):869-873. doi:10.1056/ NEJM199709253371301

8. Ng M, Fleming T, Robinson M, et al. Global, regional, and national prevalence of overweight and obesity in children and adults during 1980-2013: a systematic analysis for the Global Burden of Disease Study 2013. Lancet. 2014;384(9945):766-781. doi:10.1016/S01406736(14)60460-8

9. Abarca-Gómez L, Abdeen ZA, Hamid ZA, et al. Worldwide trends in body-mass index, underweight, overweight, and obesity from 1975 to 2016: a pooled analysis of 2416 population-based measurement studies in 128.9 million children, adolescents, and adults. Lancet. 2017;390:2627-2642.

10. Miranda JJ, Herrera VM, Chirinos JA, et al. Major cardiovascular risk factors in Latin America: a comparison with the United States. The Latin American Consortium of Studies in Obesity (LASO). PLoS One. 2013;8(1):e54056. doi:10.1371/journal.pone.0054056

11. Ramos Clason EC. Transición epidemiológica en Colombia: de las enfermedades infecciosas a las no transmisibles. Rev Cienc Biomed. 2012;3:282-290.

12. Corvalan C, Garmendia ML, Jones-Smith J, et al. Nutrition status of children in Latin America. Obes Rev. 2017;18(Suppl 2):7-18. doi:10.1111/obr.12571

13. Ogden CL, Fryar CD, Hales CM, Carroll MD, Aoki Y, Freedman DS. Differences in obesity prevalence by demographics and urbanization in US children and adolescents, 2013-2016. JAMA. 2018;319 (23):2410-2418. doi:10.1001/jama.2018.5158 
14. Jones-Smith JC, Gordon-Larsen P, Siddiqi A, Popkin BM. Is the burden of overweight shifting to the poor across the globe? Time trends among women in 39 low- and middle-income countries (1991-2008). Int J Obes (Lond). 2012;36(8):1114-1120. doi:10.1038/ijo.2011.179

15. Lanas F, Bazzano L, Rubinstein A, et al. Prevalence, distributions and determinants of obesity and central obesity in the southern cone of America. PLoS One. 2016;11(10):e0163727. doi:10.1371/journal. pone. 0163727

16. Boissonnet C, Schargrodsky H, Pellegrini F, et al. Educational inequalities in obesity, abdominal obesity, and metabolic syndrome in seven Latin American cities: the CARMELA Study. Eur J Cardiovasc Prev Rehabil. 2011;18(4):550-556. doi:10.1177/ 1741826710389418

17. Ogden CL, Carroll MD, Fakhouri TH, et al. Prevalence of obesity among youths by household income and education level of head of household - United States 2011-2014. MMWR Morb Mortal Wkly Rep. 2018;67(6):186-189. doi:10.15585/mmwr.mm6706a3

18. Katzmarzyk PT, Chaput JP, Fogelholm M, et al. International Study of Childhood Obesity, Lifestyle and the Environment (ISCOLE): contributions to understanding the global obesity epidemic. Nutrients. 2019;11(4):E848. doi:10.3390/nu11040848

19. Rogers R, Eagle TF, Sheetz A, et al. The relationship between child obes, low socioeconomic status, and race/ethnicity: lessons from Massachusetts. Child Obes. 2015;11(6):691-695. doi:10.1089/chi.2015.0029

20. Profamilia, Instituto Nacional de Salud, Universidad de Antioquía, Organización Panamericana de la Salud, Instituto Colombiano de Bienestar Familiar. Encuesta Nacional de la Situación Nutricional en Colombia, ENSIN-2005. Available from: https://www.icbf.gov. co/sites/default/files/libro_2005.pdf. Accessed March 26, 2020.

21. Profamilia, Instituto Nacional de Salud, Instituto Colombiano de Bienestar Familiar. Encuesta Nacional de la Situación Nutricional en Colombia, ENSIN-2010. Available from: https://www.icbf.gov. co/sites/default/files/resumenfi.pdf. Accessed March 26, 2020

22. Ministerio de Salud y Protección Social. Encuesta Nacional de la Situación Nutricional en Colombia ENSIN -2015. Available from: https://www.minsalud.gov.co/sites/rid/Lists/BibliotecaDigital/RIDE/ VS/ED/GCFI/ensin-colombia-2018.pdf. Accessed December 2, 2019.

23. Rivera JA, de Cossio TG, Pedraza LS, Aburto TC, Sanchez TG, Martorell R. Childhood and adolescent overweight and obesity in Latin America: a systematic review. Lancet Diabetes Endocrinol. 2014;2(4):321-332. doi:10.1016/S2213-8587(13)70173-6

24. Bushnell D, Hudson RA. Social Strata Division. In: Hudson RA, editor. Colombia: A Country Study. 5th ed. Washington, D.C. Federal Research Division, Library of Congress; 2010:101-103.

25. Departamento Administrativo Nacional de Estadística. Metodología de Estratificación Socioeconómica Urbana para Servicios Públicos Domiciliarios. Bogotá, Colombia: DANE; 2015. Available from: https://www.dane.gov.co/files/geoestadistica/estratificacion/ ManualdeRealizacion.pdf. Accessed March 30, 2020.

26. WHO Multicentre Growth Reference Study Group. Body-mass-index -for-age standards. Available from: https:/www.who.int/childgrowth/ standards/bmi_for_age/en/. Accessed March 30, 2020.

27. Aschner P, Buendia R, Brajkovich I, et al. Determination of the cutoff point for waist circumference that establishes the presence of abdominal obesity in Latin American men and women. Diabetes Res Clin Pract. 2011;93(2):243-247. doi:10.1016/j.diabres.2011.05.002

28. Albala C, Corvalan C. Epidemiology of obesity in children in South America. In: Moreno L, Pigeot I, Ahrens W, editors. Epidemiology of Obesity in Children and Adolescents. New York: Springer; 2011:95-110.

29. Pajuelo-Ramírez J, Miranda-Cuadros M, Campos-Sánchez M, Sánchez-Abanto J. Prevalencia de sobrepeso y obesidad en niños menores de cinco años en el Perú 2007-2010. Rev Peru Med Exp Salud Publica. 2011;28(2):222-227. doi:10.1590/S172646342011000200008
30. Araujo C, Toral N, da Silva ACF, Velasquez-Melendez G, Dias AJR. Nutritional status of adolescents and its relation with socio-demographics variables: national adolescent school-based health survey (PeNSE), 2009. Cien Saude Colet. 2010;15 Suppl 2 (Suppl 2):3077-3084. doi:10.1590/s1413-81232010000800012

31. Hernández M, Rivera J, Shamah T, et al. Encuesta Nacional de Salud y Nutrición de Medio Camino 2016 (ENSANUT 2016). Informe Final de Resultados. Cuernavaca, Mexico: Instituto Nacional de Salud Pública; 2016.

32. Pienaar AE. Prevalence of overweight and obesity among primary school children in a developing country: NW-CHILD longitudinal data of 6-9-yr-old children in South Africa. BMC Obes. 2015;2(1):2. doi:10.1186/s40608-014-0030-4

33. McMurray RG1, Soares J, Caspersen CJ, McCurdy T. Examining variations of resting metabolic rate of adults: a public health perspective. Med Sci Sports Exerc. 2014;46(7):1352-1358. doi:10.1249/MSS.0000000000000232

34. Kapoor E, Collazo-Clavell ML, Faubion SS. Weight gain in women at midlife: a concise review of the pathophysiology and strategies for management. Mayo Clin Proc. 2017;92(10):1552-1558. doi:10.1016/ j.mayocp. 2017.08 .004

35. Ameye H, Swinnen J. Obesity, income and gender: the changing global relationship. Glob Food Secur. 2019;23:267-281. doi:10.1016/j.gfs.2019.09.003

36. Ford ND, Patel SA, Narayan KMV. Obesity in low- and middle-income countries: burden, drivers, and emerging challenges. Annu Rev Public Health. 2017;38(1):145-164. doi:10.1146/annurevpublhealth-031816-044604

37. Popkin BM, Slining MM. New dynamics in global obesity facing low- and middle-income countries. Obes Rev. 2013;14(Suppl 2):11-20. doi:10.1111/obr.12102

38. Mendivil CO, Sierra ID, Pérez CE. Valoración del riesgo cardiovascular global y prevalencia de dislipemias según los criterios del NCEP-ATP III en una población adulta de Bogotá, Colombia. Clin Investig Arterioscler. 2004;16:99-107.

39. Ruiz AJ, Aschner PJ, Puerta MF, Cristancho RA. Estudio IDEA (International Day for Evaluation of Abdominal Obesity): prevalencia de obesidad abdominal y factores de riesgo asociados en atención primaria en Colombia. Biomédica. 2012;32(4):610-616. doi:10.7705/ biomedica.v32i4.799

40. Lanas F, Avezum A, Bautista LE, et al. Risk factors for acute myocardial infarction in Latin America: the INTERHEART Latin American study. Circulation. 2007;115(9):1067-1074. doi:10.1161/ CIRCULATIONAHA.106.633552

41. The World Bank. (2019). GNI per capita, Atlas method. Availabe from: https://data.worldbank.org/indicator/NY.GNP.PCAP.CD. Accessed Dec ember 2, 2019.

42. Cortés A. Inequidad, pobreza y salud. Colomb Med. 2006;37:223-227.

43. Jones-Smith JC, Gordon-Larsen P, Siddiqi A, Popkin BM. Emerging disparities in overweight by educational attainment in Chinese adults (1989-2006). Int J Obes (Lond). 2012;36(6):866-875. doi:10.1038/ ijo.2011.134

44. Monteiro CA, Moura EC, Conde WL, Popkin BM. Socioeconomic status and obesity in adult populations of developing countries: a review. Bull World Health Organ. 2004;82(12):940-946.

45. Torun B. Energy requirements of children and adolescents. Public Health Nutr. 2005;8(7a):968-993. doi:10.1079/PHN2005791

46. Villareal DT, Apovian CM, Kushner RF, Klein S. Obesity in older adults: technical review and position statement of the American Society for Nutrition and NAASO, The Obesity Society. Am J Clin Nutr. 2005;82(5):923-934. doi:10.1093/ajcn/82.5.923

47. Hales CM, Carroll MD, Fryar CD, Ogden CL. Prevalence of Obesity Among Adults and Youth: United States, 2015-2016. NCHS Data Brief, No 288. Hyattsville, MD: National Center for Health Statistics; 2017. 
48. Hankinson AL, Daviglus ML, Bouchard C, et al. Maintaining a high physical activity level over 20 years and weight gain. JAMA. 2010;304(23):2603-2610. doi:10.1001/jama.2010.1843

49. Popkin BM, Adair LS, Ng SW. Global nutrition transition and the pandemic of obesity in developing countries. Nutr Rev. 2012;70 (1):3-21. doi:10.1111/j.1753-4887.2011.00456.x
50. Jiwani SS, Carrillo-Larco RM, Hernández-Vásquez A, et al. The shift of obesity burden by socioeconomic status between 1998 and 2017 in Latin America and the Caribbean: a cross-sectional series study. Lancet Glob Health. 2019;7(12):e1644-54. doi:10.1016/S2214-109X(19)30421-8

51. Chooi YC, Ding C, Magkos F. The epidemiology of obesity. Metabolism. 2019;92:6-10. doi:10.1016/j.metabol.2018.09.005

\section{Publish your work in this journal}

Diabetes, Metabolic Syndrome and Obesity: Targets and Therapy is an international, peer-reviewed open-access journal committed to the rapid publication of the latest laboratory and clinical findings in the fields of diabetes, metabolic syndrome and obesity research. Original research, review, case reports, hypothesis formation, expert opinion and commentaries are all considered for publication. The manuscript management system is completely online and includes a very quick and fair peer-review system, which is all easy to use. Visit http://www.dovepress.com/testimonials.php to read real quotes from published authors. 